\title{
The Relation Between easyCBM and Smarter Balanced Reading and Mathematics Assessments
}

\author{
Julie Alonzo \\ University of Oregon
}

terventions. In the spring, a third benchmark assessment is normally given, enabling districts to evaluate the effectiveness of their instructional program and track progress made throughout the year.

Most districts that have adopted RTI often use one of several commercially available interim formative assessment systems. One such system, easyCBM, offers both literacy and mathematics assessments with built-in Spanish language supports for students in grades K-8. As of November 8, 2015, the system was used by over 500,000 teachers, representing 4.6 million students in schools and districts spread across every state in the country. They collectively took over 28.2 million measures from grades $\mathrm{K}-8$ in reading and mathematics (Anderson et al., 2014).

The easyCBM assessments are an integral part of many school districts' RTI processes (Alonzo, Tindal, Ulmer, \& Glasgow, 2006). In RTI, districts administer screening assessments, also known as benchmark assessments, three times each year, using the data to identify students at risk who might benefit from additional supports and targeted interventions. Although the system includes both benchmarking and progress monitoring assessments, only data from the benchmark assessments are included in this study. This is because the progress monitoring assessments tend to be administered only to those students identified as at -risk, whereas the benchmark assessments are universally administered to all students enrolled within a district.

The easyCBM assessment system includes two types of mathematics tests: one type which is aligned to the National Council of Teachers of Mathematics Focal Point Standards and another which is aligned to the Common Core State Standards in Mathematics (CCSS Math). The easyCBM CCSS Math benchmark assessments consist of 40 (grades 4-5) to 45 (grades 68 ) selected-response items in which students are presented with a math problem and prompted to select 
the best answer choice from three possible solutions.

These measures are designed to be taken online, although paper-pencil administration options also exist. The assessments are administered to students by their classroom teachers in either school computer labs or in regular classrooms using laptop computers provided by the school. Students earn one point for every item they answer correctly. Partial credit is not awarded; thus, possible scores range from $0-40$ in grades $4-5$ and $0-45$ in grades $6-8$. The CCSS Math measures are reported to have strong reliability evidence, with Cronbach's Alpha ranging from .90 to 95 and split-half reliability ranging from .79 to .95 in grades 4 through 8 (Wray, Alonzo, \& Tindal, 2014).

In addition to the math tests, the easyCBM system provides a variety of reading assessments. The passage reading fluency (PRF) assessment consists of original works of narrative fiction, ranging in length from 250-350 words. Students are asked to read aloud from stories presented on a single-sided sheet of paper while assessors follow along on their own copy. Assessors mark any word read incorrectly or skipped, while students read aloud for 60 seconds. Selfcorrections are not counted as errors. At the end of 60 seconds, assessors mark the last word read and subtract the number of errors to compute the final score of correct words read per minute. Prior studies have reported alternate-form reliability ranging from .87 to .96 (Alonzo \& Tindal, 2009) and .83 to .98 (Alonzo, Lai, Anderson, Park, \& Tindal, 2012) and test-retest reliability ranging from .86 to .96 (Alonzo et al., 2012). The correlations between PRF and the Oregon Assessment of Knowledge and Skills (OAKS), the state test used in Oregon prior to adoption of Smarter Balanced (SB), were generally high, ranging from .55 to .69 . Anderson, Alonzo, and Tindal (2011) reported correlations between the winter PRF measure and the spring state test used in Washington State prior to the adoption of SB, the Measures of Student Progress (MSP), ranging from .46 to .64 .

The easyCBM vocabulary assessments are selectedresponse items where students are presented with a sentence with a missing word or phrase, or one in which a word or phrase is bolded and students are asked to select the answer option that best fits the specific prompt from three possible answer choices. Students earn one point for every correct answer they provide for a total possible score of 0 to 20. These assessments are designed for online administration with responses automatically scored by the computer but are also available in a paper-pencil format. Cronbach's Alpha for the easyCBM vocabulary measures ranges from .76 to .84 , with a median of .81 for all vocabulary measures in both the fall and winter. Split-half reliabilities ranged from .61 to .75 for the first and second half of the measures, with a median of .66 and .69 , respectively. The correlation between the two halves ranged from .58 to .72, with a median correlation of .64 (Wray et al., 2014).

The easyCBM Multiple Choice Reading Comprehension (MCRC) measures consist of original works of narrative fiction ranging of approximately 1,500 words in length, followed by 20 selected-response items in which students select the answer choice they believe is the best option out of the three possible responses. Students earn one point for every correct answer they provide for a total possible score of 0 to 20 . Correlations between the easyCBM MCRC measures and the OAKS, the State tests used in Oregon before SB adoption, ranged from .55 to .67 in the fall and .44 to .61 in the winter (Sáez et al., 2010). They ranged from .52 to .65 in the fall and from .41 to .71 in the winter between the MCRC and MSP, Washington's former state-wide assessment (Tindal, Nese, \& Alonzo, 2009).

With the adoption of the SB assessments across numerous states, it is important to evaluate the relation between the SB assessments and widely-adopted interim-formative assessment systems such as easyCBM. This manuscript presents the initial findings of one such study.

\section{Methodology}

Data for this study came from a convenience sample provided by two school districts in the Pacific Northwest. All students enrolled in school and present during the three-week easyCBM Benchmark Assessment windows in the fall (September, 2014), winter (January, 2015), and spring (May, 2015) were administered easyCBM assessments. All enrolled students were likewise administered the SB assessments during the testing window provided by the state in the spring of 2015. The data set provided by the districts included easyCBM CCSS math, PRF, vocabulary, and multiple choice reading comprehension (MCRC) as well as SB math and ELA total scores for students enrolled in grades 3 through 8 . District 1 provided data for grades 3 through 8 , while District 2 provided data for grades 4 through 8 . In addition, District 1 provided demographic information, while District 2 (approximately one-fourth the size of the first district) did not. Demographics of the sample are provided in Table 1. Because of the missing demographics from a large proportion of the sample, the percentages for each of the demographic variables are calculated 
Table 1

Participant Demographics

\begin{tabular}{|c|c|c|c|c|c|c|c|c|c|c|}
\hline \multirow{2}{*}{ Grade } & \multicolumn{2}{|c|}{$\frac{\text { Missing Demo- }}{\text { graphic Data }}$} & \multicolumn{2}{|c|}{$\underline{\text { Female }}$} & \multicolumn{2}{|c|}{$\underline{\text { Hispanic }}$} & \multicolumn{2}{|c|}{$\underline{\mathrm{SpEd}}$} & \multicolumn{2}{|c|}{$\underline{\text { ELL }}$} \\
\hline & $\#$ & $\%$ & \# & $\%$ & $\#$ & $\%$ & $\#$ & $\%$ & \# & $\%$ \\
\hline 3 & 33 & 3 & 492 & 48 & 187 & 18 & 87 & 8 & 67 & 7 \\
\hline 4 & 328 & 24 & 523 & 50 & 217 & 21 & 100 & 10 & 62 & 6 \\
\hline 5 & 295 & 23 & 483 & 48 & 159 & 16 & 89 & 9 & 39 & 4 \\
\hline 6 & 291 & 22 & 505 & 49 & 180 & 17 & 95 & 9 & 27 & 3 \\
\hline 7 & 280 & 23 & 456 & 48 & 185 & 19 & 78 & 8 & 29 & 3 \\
\hline 8 & 266 & 20 & 526 & 50 & 192 & 18 & 83 & 8 & 22 & 2 \\
\hline
\end{tabular}

based on the students in the sample whose data included full-resolution demographic information. During data cleaning, data from students who were administered the alternate assessment rather than the general education assessment were removed from the dataset prior to further analyses. In all, six students each from grades 4,6 , and 7 and three students from grade 5 were removed from the dataset in this step. Data from all additional students were retained.

\section{Measures}

The data set provided for this study included scores from the fall 2014, winter 2015, and spring 2015 easyCBM CCSS math, PRF, vocabulary benchmark assessments. Data were also from the fall 2014 and winter 2015 MCRC benchmark assessments, as well as from the 2015 SB mathematics and ELA total scores.

\section{Data Analysis}

For this study, the relations between the easyCBM benchmark assessments and the SB assessments were analyzed using bivariate correlations as well as linear regression. The results for the mathematics assessments are presented first, followed by the results for the individual reading assessments (i.e., PRF, then vocabulary, and finally MCRC), and then the reading assessments as a whole. Scatterplots of the bivariate correlations are also presented. To further aid in interpreting the results, horizontal lines have been added to the scatterplots to depict the cut score for "proficient" on the SB assessment, as well as vertical lines to indicate the scores that correspond with the 50th, 75th, and 90th percentile scores, respectively, on the easyCBM assessments.

\section{Results}

Results for the math assessments are presented first, followed by the literacy assessments. Demographic statistics for the math sample are presented in Table 2 and for the reading sample in Tables 3 through 5 (Tables 2-13 and Figures 1-4 are located in Appendix A and B, respectively).

\section{Relation between easyCBM CCSS Math Bench- marks and SB Total Math}

The easyCBM CCSS math benchmark assessments had a moderate-to-strong positive correlation with the SB total math score, ranging from a low of 69 (grade 3 , fall) to a high of .84 (grade 6, spring), with the relation getting stronger as grade level increased (See Table 6). Correlation results were then graphed on a series of scatterplots with a horizontal line to delineate the cut score on SB at which a student is deemed proficient and vertical lines to indicate the scores that correspond with the 50th, 75th, and 90th percentile rank, based on the easyCBM national norms published by easyCBM (Saven, Tindal, Irvin, Farley, \& Alonzo, 2014). These scatterplots are presented in Figure 1.

At all grade levels, the CCSS math seasonal benchmark assessments were significant predictors of students' performance on the SB mathematics assessment (See Table 7). The proportion of variance on the SB mathematics assessment accounted for by students' performance on the easyCBM CCSS math assessments varied from a low of $68 \%$ (grade 4 ) to a high of $77 \%$ (grade 6). 


\section{Relation between easyCBM PRF Benchmarks and SB ELA Total}

The easyCBM PRF benchmark assessments had a moderate positive correlation with the SB Total ELA Score (See Table 8). Correlations ranged from a low of .56 (grade 8 , fall) to a high of .68 (grade 5, fall). The most consistently high correlations were found in grade 5, where the correlation between PRF and SB ELA total score remained in the high .60 's across all three seasonal benchmarks.

Correlation results were then graphed on a series of scatterplots, with a horizontal line to delineate the cut score on SB at which a student is deemed proficient and vertical lines to indicate the scores that correspond with the 50th, 75th, and 90th percentile rank, based on the easyCBM national norms published by easyCBM (Saven et al., 2014). These scatterplots are presented in Figure 2.

\section{Relation between easyCBM Vocabulary Benchmarks and SB ELA Total}

The easyCBM vocabulary benchmark assessments had a moderate-to-strong positive correlation with the SB Total ELA Score (see Table 9). Correlations range from a low of .58 (grade 4, spring) to a high of .69 (grade 5, fall). Correlation results were then graphed on a series of scatterplots, with a horizontal line to delineate the cut score on SB at which a student is deemed proficient and vertical lines to indicate the scores that correspond with the 50th, 75th, and 90th percentile rank, based on the easyCBM national norms published by easyCBM (Saven et al., 2014). These scatterplots are presented in Figure 3.

\section{Relation between easyCBM MCRC Benchmarks and SB ELA Total}

The easyCBM MCRC benchmark assessments had a moderate-to-strong positive correlation with the SB total ELA score (See Table 10). Correlations ranged from a low of .50 (grade 6, winter) to a high of .68 (grade 4, fall and grade 5, winter). Correlation results were then graphed on a series of scatterplots, with a horizontal line to delineate the cut score on SB at which a student is deemed proficient and vertical lines to indicate the scores that correspond with the 50th, 75th, and 90th percentile rank, based on the easyCBM national norms published by easyCBM (Saven et al., 2014). These scatterplots are presented in Figure 4.

All of the easyCBM seasonal benchmark reading assessments were significant predictors of students' performance on the SB English language arts assess- ment across all grade levels and all three seasons. In the fall, the three easyCBM reading assessments accounted for between 50\% (grade 6) and 62\% (grade 5) of the variance on the SB ELA assessment, with the three sub-tests (i.e., PRF, vocabulary, and MCRC) uniquely accounting for roughly equal proportions of that variance (See Table 11). In the winter, the three easyCBM reading assessments accounted for between $53 \%$ (grade 8 ) and $60 \%$ (grade 5 ) of the variance on the SB ELA assessment, with the three sub-tests (i.e., PRF, vocabulary, and MCRC) uniquely accounting for roughly equal proportions of that variance (See Table 12).

In the spring, the three easyCBM reading assessments accounted for between $52 \%$ (grades 4 and 6) and $59 \%$ (grade 7) of the variance on the SB ELA assessment, with the three sub-tests (i.e., PRF, vocabulary, and MCRC) uniquely accounting for roughly equal proportions of that variance (See Table 13).

\section{Discussion}

This study provides promising evidence for districts interested in knowing the degree to which the easyCBM assessments provide useful guidance in terms of how well students are prepared for meeting the demands of the Smarter Balanced Assessments in mathematics and ELA. However, it is important to point out several limitations with the current study. The largest limitation relates to the sample used in these analyses. Although the initial results are promising, the sample used comes from only two districts located in the Pacific Northwest (in some cases slightly fewer than 1,000 students for a particular analysis). To the extent that the demographics of the districts supplying the data differ in substantive ways from districts to which the results are being extended, caution is warranted.

Despite this caution related to the sample, this study provides some reason for optimism. The results suggest the relation between the easyCBM CCSS math and reading assessments is actually slightly stronger than that reported in earlier studies examining the relation between the easyCBM assessments and state tests in Oregon (Sáez et al., 2010; Tindal et al., 2009) and Washington (Anderson et al., 2011). Based on these results, districts interested in an interim formative assessment system that can be used to predict performance on the SB assessment should have a degree of confidence that the easyCBM assessments are predictive of students' performance on SB assessments.

The easyCBM CCSS math tests, in particular, ap- 
pear to be very strong predictors of performance on the SB math assessments across all grades examined. A concern that some educators have expressed is that traditional selected response math items, such as those used on the easyCBM CCSS math tests, may not be sufficient for predicting how students will perform on more innovative math items, such as those included on SB. Based on the results of this study, these concerns appear unwarranted.

One consideration that does warrant concern is the higher expectation for performance required to be deemed proficient on the SB assessment than on previous state assessments in both Oregon and Washington and likely in other states as well. Whereas in the past, recommendations for identifying students as low -risk based on their easyCBM performance focused on scores at or above the 50th percentile rank (Anderson et al., 2011; Tindal et al., 2009), visual inspection of the scatterplots suggest that this criteria is insufficient when trying to predict proficient performance on SB assessments. Rather, performance closer to the 75th percentile may be needed for students to consistently be deemed proficient on SB. This finding holds true across all grades, assessment types, and seasonal benchmarks. This finding is particularly interesting in that it highlights the expectations for "above average" performance for students to be considered proficient on the SB mathematics and ELA assessments.

The easyCBM norms were established in 2014 using a nationally-representative sample of students in grades K-8 with demographics matching the demographics of the school-aged population. The samples were drawn in equal proportions from the four regions of the United States used in National Center of Education Statistics reporting (Saven et al., 2014). The scores on easyCBM at the 50th percentile represent the point at which half of the student population would be expected to perform. Based on the results of this study, it is clear that performance at this level is insufficient to ensure students will meet expectations on the SB assessments. The current cut scores for SB assume students who "meet benchmark expectations" will out-perform approximately $75 \%$ of their peers. It is beyond the scope of this study to speculate on whether this expectation is a reasonable one. However, it is important that school administrators be aware that expectations for performance level, as well as for content covered, may have shifted.

\section{References}

Alonzo, J., Lai, C. F., Anderson, D., Park, B. J., \& Tindal, G. (2012). An examination of test-retest, alternate form reliability, and generalizability theory study of the easyCBM reading assessments: Grade 4 (Technical Report 1219). Eugene, OR: Behavioral Research and Teaching, University of Oregon.

Alonzo, J., \& Tindal, G. (2009). Alternate form and test-retest reliability of easyCBM reading measures (Technical Report 0906). Eugene, OR: Behavioral Research and Teaching, University of Oregon.

Alonzo, J., Tindal, G., Ulmer, K., \& Glasgow, A. (2006). easyCBM online progress monitoring assessment system. http:// easycbm.com. Eugene, OR: Center for Educational Assessment Accountability.

Anderson, D., Alonzo, J., \& Tindal, G. (2011). easyCBM reading criterion related to validity evidence: Washington state test 20092010 (Technical Report 1101). Eugene, OR: Behavioral Research and Teaching, University of Oregon.

Anderson, D., Alonzo, J., Tindal, G., Farley, D., Irvin, P. S., Lai, C. F., Saven, J. L., Wray, K. A. (2014). Technical Manual: easyCBM (Technical Report No. 1408). Eugene, OR: Behavioral Research and Teaching, University of Oregon.

Sáez, L., Park, B. J., Nese, J. F. T., Jamgochian, E. M., Lai, C. F., Anderson, D., et al. (2010). Technical adequacy of the easyCBM reading measures (Grades 3-7), 2009-2010 version (Technical Report 1005). Eugene, OR: Behavioral Research and Teaching, University of Oregon.

Saven, J. L., Tindal, G., Irvin, P. S., Farley, D., \& Alonzo, J. (2014). easyCBM norms 2014 edition. (Technical Report No. 1409). Eugene, OR: Behavioral Research and Teaching, University of Oregon.

Tindal, G., Nese, J. T., \& Alonzo, J. (2009). Criterion-related evidence using easy CBM $®$ reading measures and student demographics to predict state test performance in grades 3-8 (Technical Report No. 0910). Eugene, OR: Behavioral Research and Teaching, University of Oregon.

Wray, K., Alonzo, J., \& Tindal, G. (2014). Internal consistency of the easyCBM Measures, Grades 2-8. Eugene, OR: University of Oregon, Behavorial Research and Teaching. 


\section{Appendix A}

Table 2

Descriptive Statistics: easyCBM Mathematics and Smarter Balanced Math

\begin{tabular}{|c|c|c|c|c|c|c|c|c|c|c|c|c|}
\hline \multirow{2}{*}{$\underline{\text { Gr. }}$} & \multicolumn{3}{|c|}{ easyCBM CCSS Math Fall } & \multicolumn{3}{|c|}{$\frac{\text { easyCBM CCSS Math }}{\underline{\text { Fall }}}$} & \multicolumn{3}{|c|}{$\frac{\text { easyCBM CCSS Math }}{\underline{\text { Fall }}}$} & \multicolumn{3}{|c|}{$\frac{\text { Smarter Balanced Total }}{\underline{\text { Math }}}$} \\
\hline & $n$ & $M$ & $S D$ & $n$ & $M$ & $S D$ & $n$ & $M$ & $S D$ & $n$ & $M$ & $S D$ \\
\hline 3 & 979 & 25.45 & 5.23 & 1028 & 29.62 & 5.67 & 1034 & 32.97 & 4.91 & 1051 & 2441 & 70.78 \\
\hline 4 & 1275 & 25.54 & 6.13 & 1322 & 28.27 & 5.94 & 1344 & 31.10 & 6.02 & 1364 & 2481 & 74.48 \\
\hline 5 & 1215 & 23.51 & 6.08 & 1252 & 27.16 & 6.18 & 1185 & 28.66 & 6.96 & 1297 & 2510 & 83.03 \\
\hline 6 & 1233 & 24.37 & 6.68 & 1286 & 27.59 & 7.12 & 1304 & 30.26 & 7.87 & 1318 & 2522 & 89.89 \\
\hline 7 & 1141 & 23.49 & 6.77 & 1176 & 27.05 & 8.11 & 1205 & 28.28 & 8.53 & 1228 & 2544 & 98.83 \\
\hline 8 & 1098 & 22.91 & 7.64 & 1213 & 27.89 & 8.20 & 1216 & 29.15 & 8.99 & 1302 & 2560 & 109.2 \\
\hline
\end{tabular}

Table 3

Descriptive Statistics: easyCBM Fall Reading Measures and Smarter Balanced ELA

\begin{tabular}{|c|c|c|c|c|c|c|c|c|c|c|c|c|}
\hline \multirow{2}{*}{$\underline{\text { Gr. }}$} & \multicolumn{3}{|c|}{ easyCBM PRF } & \multicolumn{3}{|c|}{ easyCBM Voc } & \multicolumn{3}{|c|}{$\underline{\text { easyCBM MCRC }}$} & \multicolumn{3}{|c|}{$\frac{\text { Smarter Balanced Total }}{\underline{\text { ELA }}}$} \\
\hline & $n$ & $M$ & $S D$ & $n$ & $M$ & $S D$ & $n$ & $M$ & $S D$ & $n$ & $M$ & $S D$ \\
\hline 3 & 977 & 89.32 & 37.34 & 967 & 14.83 & 3.92 & 972 & 10.83 & 3.61 & 1056 & 2227 & 77.35 \\
\hline 4 & 1184 & 108.05 & 35.49 & 1181 & 15.50 & 3.76 & 1183 & 11.71 & 3.98 & 1359 & 2462 & 81.72 \\
\hline 5 & 1220 & 140.63 & 44.03 & 1201 & 15.61 & 3.55 & 1210 & 13.12 & 3.67 & 1294 & 2502 & 85.35 \\
\hline 6 & 1199 & 143.96 & 39.38 & 1240 & 16.65 & 3.03 & 1244 & 14.19 & 3.21 & 1320 & 2522 & 83.04 \\
\hline 7 & 1119 & 153.69 & 35.58 & 1137 & 17.00 & 2.98 & 1141 & 13.55 & 3.39 & 1220 & 2549 & 89.63 \\
\hline 8 & 1211 & 173.26 & 37.65 & 1236 & 17.38 & 2.75 & 1238 & 14.07 & 3.34 & 1294 & 2577 & 90.89 \\
\hline
\end{tabular}


Table 4

Descriptive Statistics: easyCBM Winter Reading Measures and Smarter Balanced ELA

\begin{tabular}{|c|c|c|c|c|c|c|c|c|c|c|c|c|}
\hline \multirow{2}{*}{$\underline{\text { Gr. }}$} & \multicolumn{3}{|c|}{$\underline{\text { easyCBM PRF }}$} & \multicolumn{3}{|c|}{$\underline{\text { easyCBM Voc }}$} & \multicolumn{3}{|c|}{$\underline{\text { easyCBM MCRC }}$} & \multicolumn{3}{|c|}{$\frac{\text { Smarter Balanced Total }}{\text { ELA }}$} \\
\hline & $n$ & $M$ & $S D$ & $n$ & $M$ & $S D$ & $n$ & $M$ & $S D$ & $n$ & $M$ & $S D$ \\
\hline 3 & 1010 & 124.68 & 41.91 & 1019 & 16.22 & 3.58 & 1014 & 10.47 & 2.96 & 1056 & 2227 & 77.35 \\
\hline 4 & 1228 & 134.17 & 37.12 & 1229 & 16.66 & 3.16 & 1225 & 13.54 & 3.45 & 1359 & 2462 & 81.72 \\
\hline 5 & 1252 & 154.46 & 41.93 & 1244 & 16.35 & 3.02 & 1246 & 15.21 & 3.64 & 1294 & 2502 & 85.35 \\
\hline 6 & 1236 & 160.85 & 42.22 & 1284 & 16.86 & 3.04 & 1282 & 14.23 & 3.14 & 1320 & 2522 & 83.04 \\
\hline 7 & 1173 & 171.94 & 42.02 & 1177 & 17.20 & 2.72 & 1175 & 14.24 & 3.06 & 1220 & 2549 & 89.63 \\
\hline 8 & 1257 & 170.57 & 39.59 & 1262 & 17.22 & 2.52 & 1266 & 13.09 & 3.19 & 1294 & 2577 & 90.89 \\
\hline
\end{tabular}

Table 5

Descriptive Statistics: easyCBM Spring Reading Measures and Smarter Balanced ELA

\begin{tabular}{|c|c|c|c|c|c|c|c|c|c|c|c|c|}
\hline \multirow{2}{*}{$\underline{\text { Gr. }}$} & \multicolumn{3}{|c|}{ easyCBM PRF } & \multicolumn{3}{|c|}{$\underline{\text { easyCBM Voc }}$} & \multicolumn{3}{|c|}{$\underline{\text { easyCBM MCRC }}$} & \multicolumn{3}{|c|}{$\frac{\text { Smarter Balanced Tota }}{\underline{\text { ELA }}}$} \\
\hline & $n$ & $M$ & $S D$ & $n$ & $M$ & $S D$ & $n$ & $M$ & $S D$ & $n$ & $M$ & $S D$ \\
\hline 3 & 1039 & 121.92 & 42.83 & 1024 & 17.18 & 2.84 & 1021 & 14.00 & 3.65 & 1056 & 2227 & 77.35 \\
\hline 4 & 1259 & 141.70 & 41.94 & 1249 & 17.41 & 2.75 & 1044 & 14.32 & 3.45 & 1359 & 2462 & 81.72 \\
\hline 5 & 1283 & 166.33 & 44.14 & 1276 & 16.79 & 3.01 & 1018 & 14.42 & 2.95 & 1294 & 2502 & 85.35 \\
\hline 6 & 1239 & 173.35 & 46.33 & 1288 & 17.28 & 3.05 & 1033 & 14.73 & 3.17 & 1320 & 2522 & 83.04 \\
\hline 7 & 1200 & 165.07 & 41.35 & 1150 & 16.88 & 3.11 & 922 & 11.74 & 3.10 & 1220 & 2549 & 89.63 \\
\hline 8 & 1259 & 170.48 & 37.33 & 1241 & 17.49 & 2.87 & 1006 & 12.66 & 3.40 & 1294 & 2577 & 90.89 \\
\hline
\end{tabular}


Table 6

Correlations (and n) Between easyCBM CCSS Math and SB Math Total Score

\section{$\underline{\text { Seasonal Benchmark }}$}

Grade

$\underline{\text { Fall }}$

3

4

5

6

7

8

**Correlation is significant at the .01 level. $\underline{\text { Winter }}$

$.78 * *(n=1021)$

$.74 * *(n=1321)$

$.83^{* *}(n=1248)$

$.80^{* *}(n=1281)$

$.82 * *(n=1174)$

$.80 * *(n=1208)$
Spring

$.76^{* *}(n=1031)$

$.72 * *(n=1343)$

$.78 * *(n=1184)$

$.84 * *(n=1301)$

$.79 * *(n=1204)$

$.82 * *(n=1210)$

Table 7

Linear Regression Results: Predicting Smarter Balanced Total Math from easyCBM CCSS Math

\begin{tabular}{|c|c|c|c|c|c|c|}
\hline \multirow{2}{*}{ Grade } & \multirow{2}{*}{$\underline{\mathrm{R} \text { Square }}$} & \multirow{2}{*}{$\underline{F}$} & \multirow{2}{*}{$\underline{\text { Sig }}$} & \multicolumn{3}{|c|}{$\underline{\text { Part Correlations }}$} \\
\hline & & & & $\underline{\text { Fall }}$ & $\underline{\text { Winter }}$ & Spring \\
\hline 3 & .70 & 739.50 & .000 & .16 & .24 & .24 \\
\hline 4 & .68 & 869.38 & .000 & .24 & .17 & .20 \\
\hline 5 & .74 & 1015.20 & .000 & .10 & .29 & .16 \\
\hline 6 & .77 & 1336.51 & .000 & .10 & .16 & .29 \\
\hline 7 & .75 & 1091.47 & 000 & .10 & .24 & .21 \\
\hline 8 & .76 & 1088.12 & .000 & .12 & .20 & .27 \\
\hline
\end{tabular}


Table 8

Correlations (and n) Between easyCBM Passage Reading Fluency and SB ELA Total Score

\begin{tabular}{|c|c|c|c|}
\hline \multirow{2}{*}{$\underline{\text { Grade }}$} & \multicolumn{3}{|c|}{$\underline{\text { Seasonal Benchmark }}$} \\
\hline & Fall & $\underline{\text { Winter }}$ & Spring \\
\hline 3 & $.64 * *(n=976)$ & $.64 * *(n=1009)$ & $.65^{* *}(n=1037)$ \\
\hline 4 & $.63^{* *}(n=1184)$ & $.62 * *(n=1228)$ & $.63^{* *}(n=1258)$ \\
\hline 5 & $.68^{* *}(n=1217)$ & $.67^{* *}(n=1251)$ & $.67 * *(n=1279)$ \\
\hline 6 & $.59^{* *}(n=1197)$ & $.61 * *(n=1233)$ & $.61 * *(n=1236)$ \\
\hline 7 & $.61^{* *}(n=1115)$ & $.62 * *(n=1167)$ & $.61 * *(n=1191)$ \\
\hline 8 & $.56^{* *}(n=1204)$ & $.58^{* *}(n=1248)$ & $.60 * *(n=1247)$ \\
\hline
\end{tabular}

**Correlation is significant at the .01 level.

Table 9

Correlations (and n) Between easyCBM Vocabulary and SB ELA Total Score

\section{$\underline{\text { Seasonal Benchmark }}$}

Grade

Fall

$\underline{\text { Winter }}$

Spring

3

$.68^{* *}(n=966)$

$.63 * *(n=1018)$

$.61 * *(n=1022)$

4

$.66^{* *}(n=1181)$

$.61 * *(n=1229)$

$.58 * *(n=1248)$

5

$.69^{* *}(n=1198)$

$.65^{* *}(n=1243)$

$.62 * *(n=1270)$

6

$.61 * *(n=1238)$

$.68^{* *}(n=1281)$

$.61 * *(n=1285)$

7

$.66^{* *}(n=1132)$

$.66^{* *}(n=1169)$

$.64 * *(n=1144)$

8

$.62 * *(n=1228)$

$.64 * *(n=1230)$

${ }^{* *}$ Correlation is significant at the .01 level. 
Table 10

Correlations (and n) Between easyCBM MCRC and SB ELA Total Score

\begin{tabular}{|c|c|c|c|}
\hline \multirow{2}{*}{ Grade } & \multicolumn{3}{|c|}{$\underline{\text { Seasonal Benchmark }}$} \\
\hline & Fall & Winter & Spring \\
\hline 3 & $.62 * *(n=971)$ & $.63^{* *}(n=1013)$ & $.66^{* *}(n=1019)$ \\
\hline 4 & $.68^{* *}(n=1183)$ & $.63^{* *}(n=1225)$ & $.60 * *(n=1043)$ \\
\hline 5 & $.67 * *(n=1209)$ & $.68^{* *}(n=1245)$ & $.65^{* *}(n=1017)$ \\
\hline 6 & $.58 * *(n=1242)$ & $.50 * *(n=1280)$ & $.62 * *(n=1032)$ \\
\hline 7 & $.63 * *(n=1136)$ & $.57 * *(n=1167)$ & $.61^{* *}(n=919)$ \\
\hline 8 & $.64^{* *}(n=1230)$ & $.56^{* *}(n=1256)$ & $.64 * *(n=998)$ \\
\hline
\end{tabular}

**Correlation is significant at the .01 level.

Table 11

Linear Regression Results: Predicting Smarter Balanced Total ELA from easyCBM Fall Reading Measures

\begin{tabular}{|c|c|c|c|c|c|c|}
\hline \multirow{2}{*}{ Grade } & \multirow{2}{*}{$\underline{\mathrm{R} \text { Square }}$} & \multirow{2}{*}{$\underline{F}$} & \multirow{2}{*}{$\underline{\text { Sig }}$} & \multicolumn{3}{|c|}{$\frac{\text { Proportion of Unique Variance Accounted for by }}{\text { easyCBM Measures }}$} \\
\hline & & & & $\underline{\text { PRF }}$ & $\underline{\text { Voc }}$ & $\underline{\mathrm{MCRC}}$ \\
\hline 3 & .56 & 403.34 & .000 & .17 & .23 & .20 \\
\hline 4 & .58 & 539.60 & .000 & .19 & .18 & .26 \\
\hline 5 & .62 & 645.17 & .000 & .23 & .23 & .22 \\
\hline 6 & .50 & 386.29 & .000 & .23 & .21 & .20 \\
\hline 7 & .57 & 485.84 & 000 & .23 & .23 & .23 \\
\hline 8 & .53 & 451.83 & .000 & .19 & .21 & .29 \\
\hline
\end{tabular}


Table 12

Linear Regression Results: Predicting Smarter Balanced Total ELA from easyCBM Winter Reading Measures

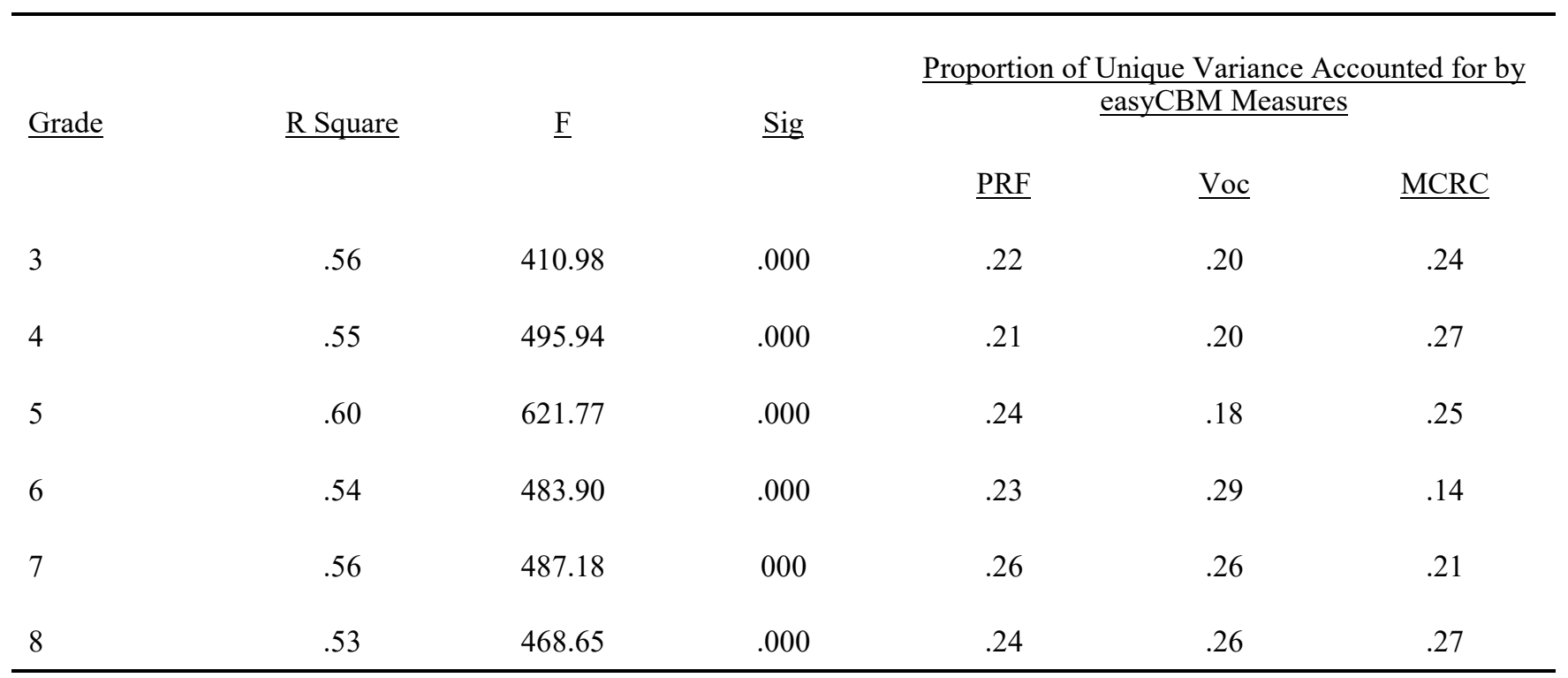

Table 13

Linear Regression Results: Predicting Smarter Balanced Total ELA from easyCBM Spring Reading Measures

\begin{tabular}{|c|c|c|c|c|c|c|}
\hline \multirow{2}{*}{$\underline{\text { Grade }}$} & \multirow{2}{*}{$\underline{\text { R Square }}$} & \multirow{2}{*}{$\underline{F}$} & \multirow{2}{*}{$\underline{\text { Sig }}$} & \multicolumn{3}{|c|}{$\begin{array}{l}\text { Proportion of Unique Variance Accounted for by } \\
\text { easyCBM Measures }\end{array}$} \\
\hline & & & & $\underline{\text { PRF }}$ & $\underline{\text { Voc }}$ & $\underline{\mathrm{MCRC}}$ \\
\hline 3 & .56 & 430.59 & .000 & .26 & .15 & .24 \\
\hline 4 & .52 & 374.78 & .000 & .26 & .19 & .21 \\
\hline 5 & .57 & 431.30 & .000 & .22 & .20 & .25 \\
\hline 6 & .52 & 346.08 & .000 & .25 & .14 & .27 \\
\hline 7 & .59 & 429.57 & 000 & .24 & .28 & .25 \\
\hline 8 & .57 & 425.37 & .000 & .24 & .23 & .30 \\
\hline
\end{tabular}




\section{Appendix B}

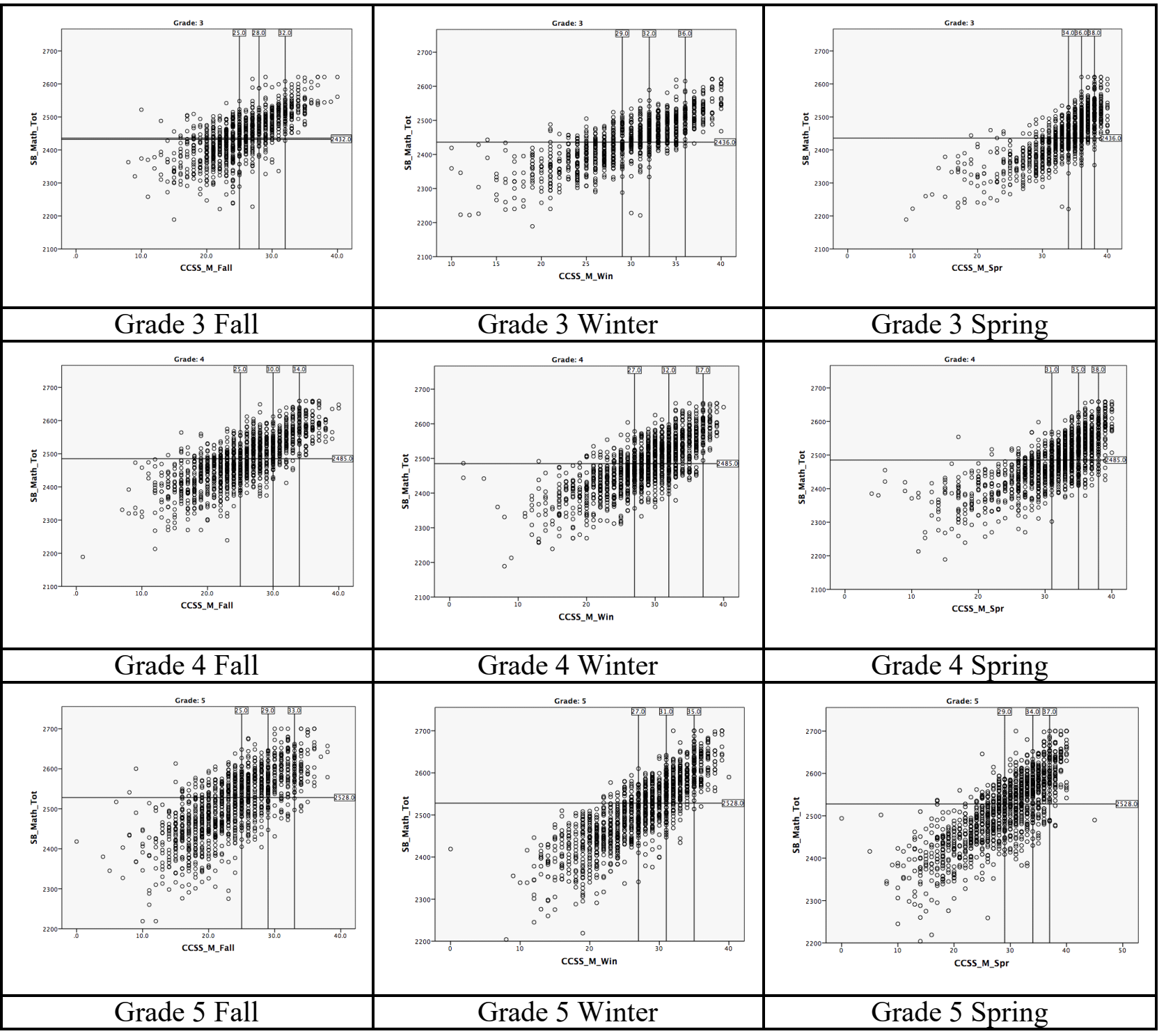

Figure 1. Scatterplots Showing Relation between easyCBM and SB Math Total Score (vertical lines indicate easyCBM norms at the $50^{\text {th }}, 75^{\text {th }}$, and $90^{\text {th }}$ percentile, from left to right; horizontal line indicates SB "Proficient" cut score). 


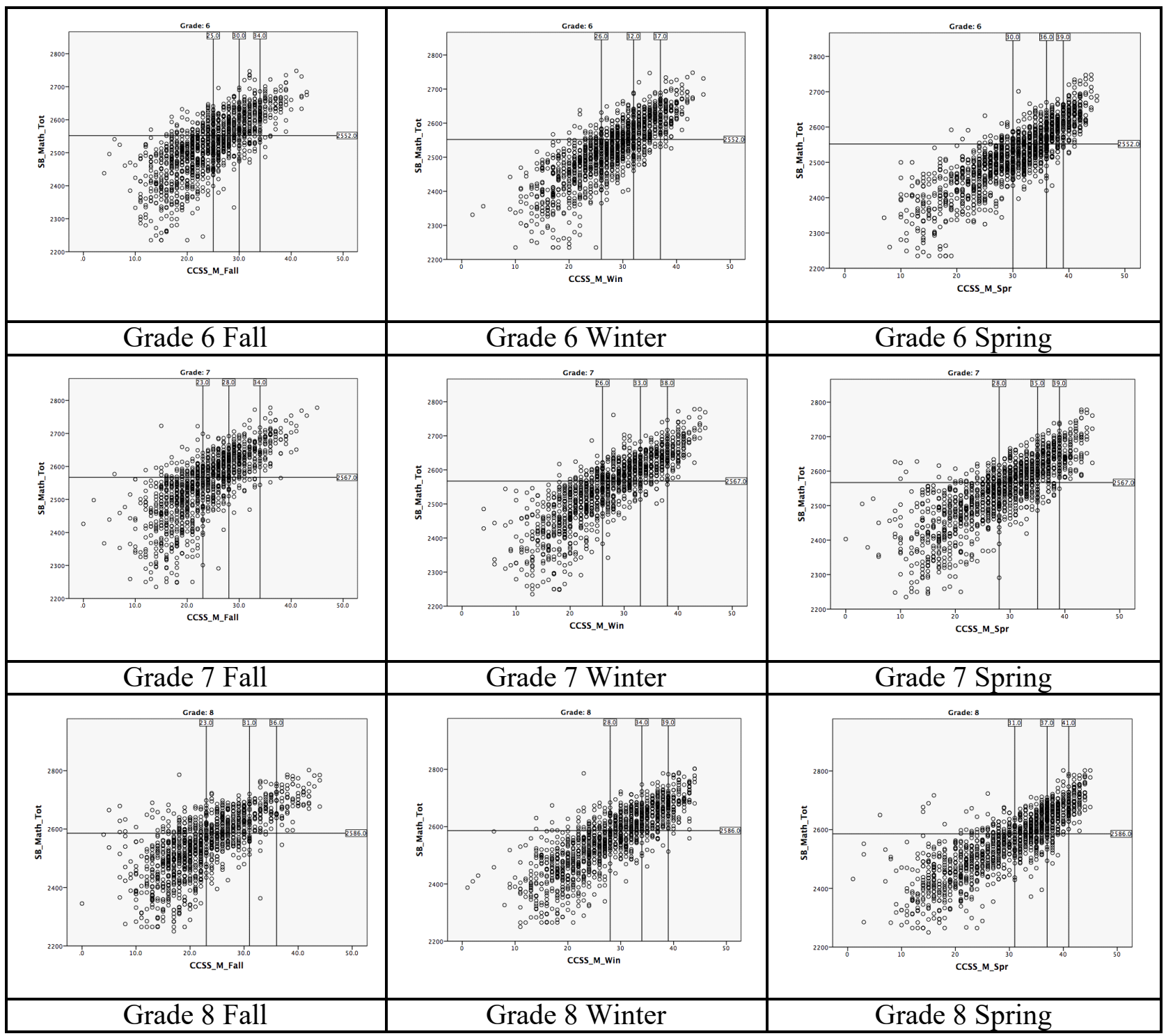

Figure 1 (continued). Scatterplots Showing Relation between easyCBM and SB Math Total Score (vertical lines indicate easyCBM norms at the $50^{\text {th }}, 75^{\text {th }}$, and $90^{\text {th }}$ percentile, from left to right; horizontal line indicates SB "Proficient" cut score). 


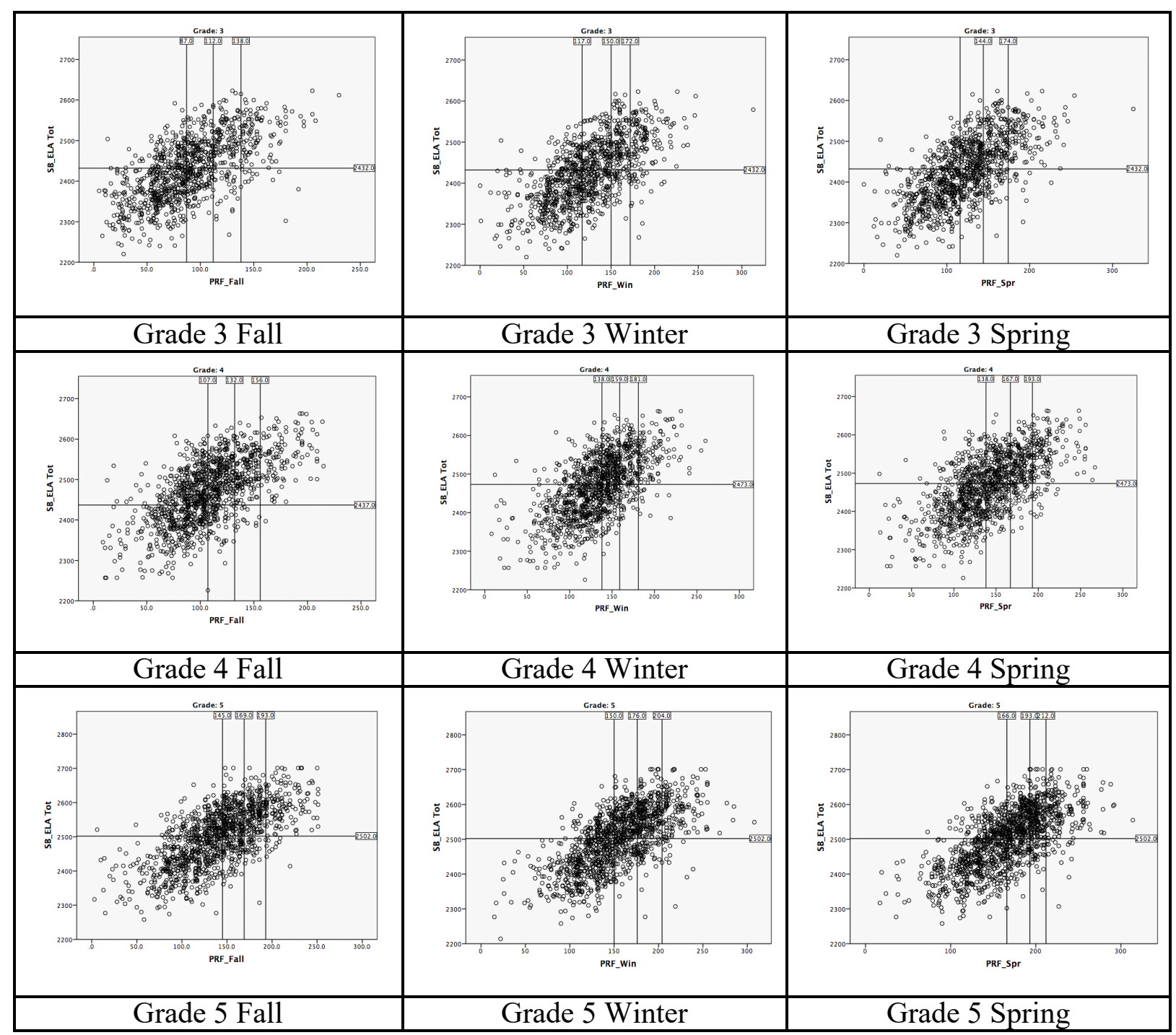

Figure 2. Scatterplots Showing Relation between easyCBM PRF and SB ELA Total Score (vertical lines indicate easyCBM norms at the $50^{\text {th }}, 75^{\text {th }}$, and $90^{\text {th }}$ percentile, from left to right; horizontal line indicates SB "Proficient" cut score). 


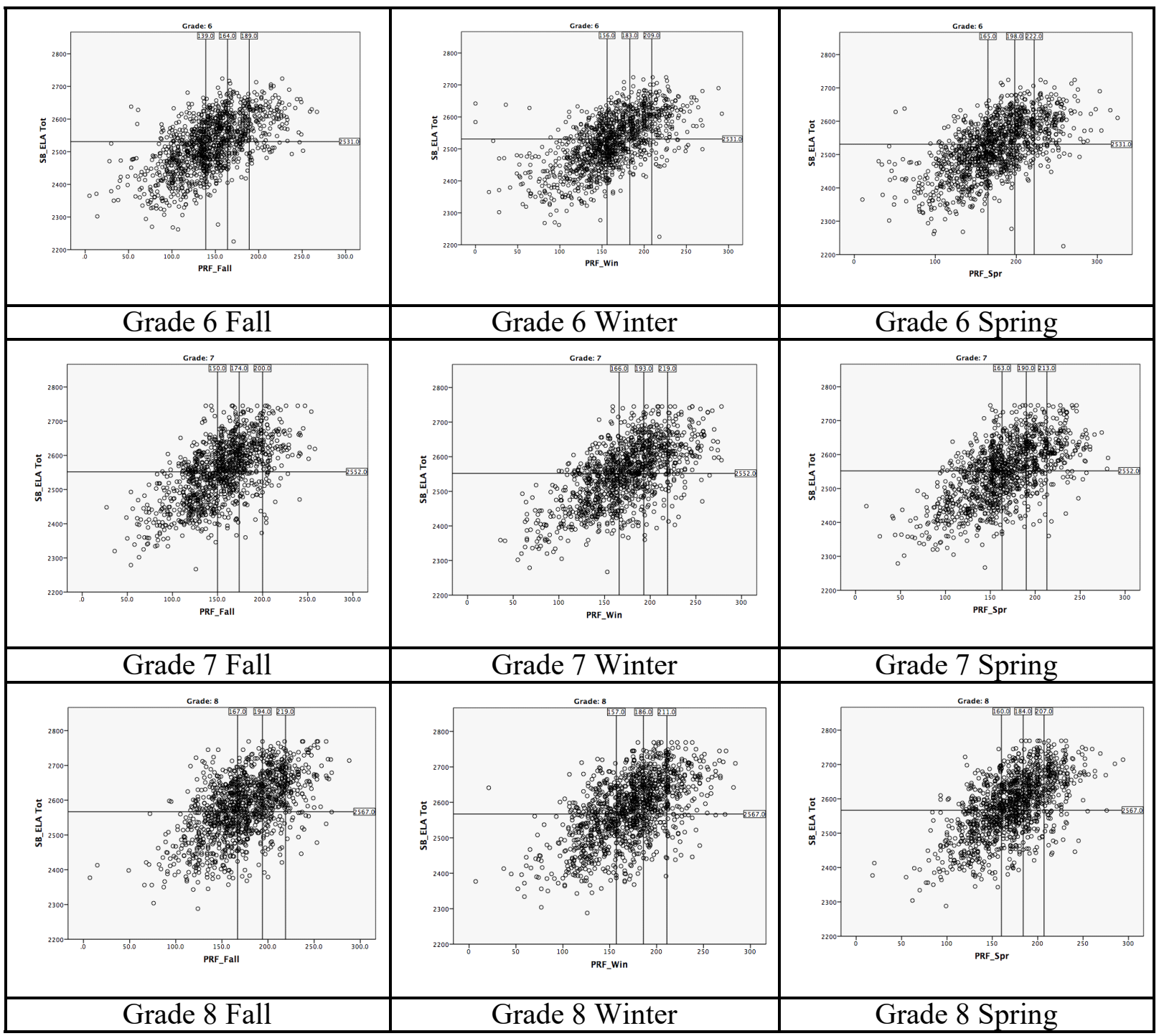

Figure 2 (Continued). Scatterplots Showing Relation between easyCBM PRF and SB ELA Total Score (vertical lines indicate easyCBM norms at the $50^{\text {th }}, 75^{\text {th }}$, and $90^{\text {th }}$ percentile, from left to right; horizontal line indicates SB "Proficient" cut score). 


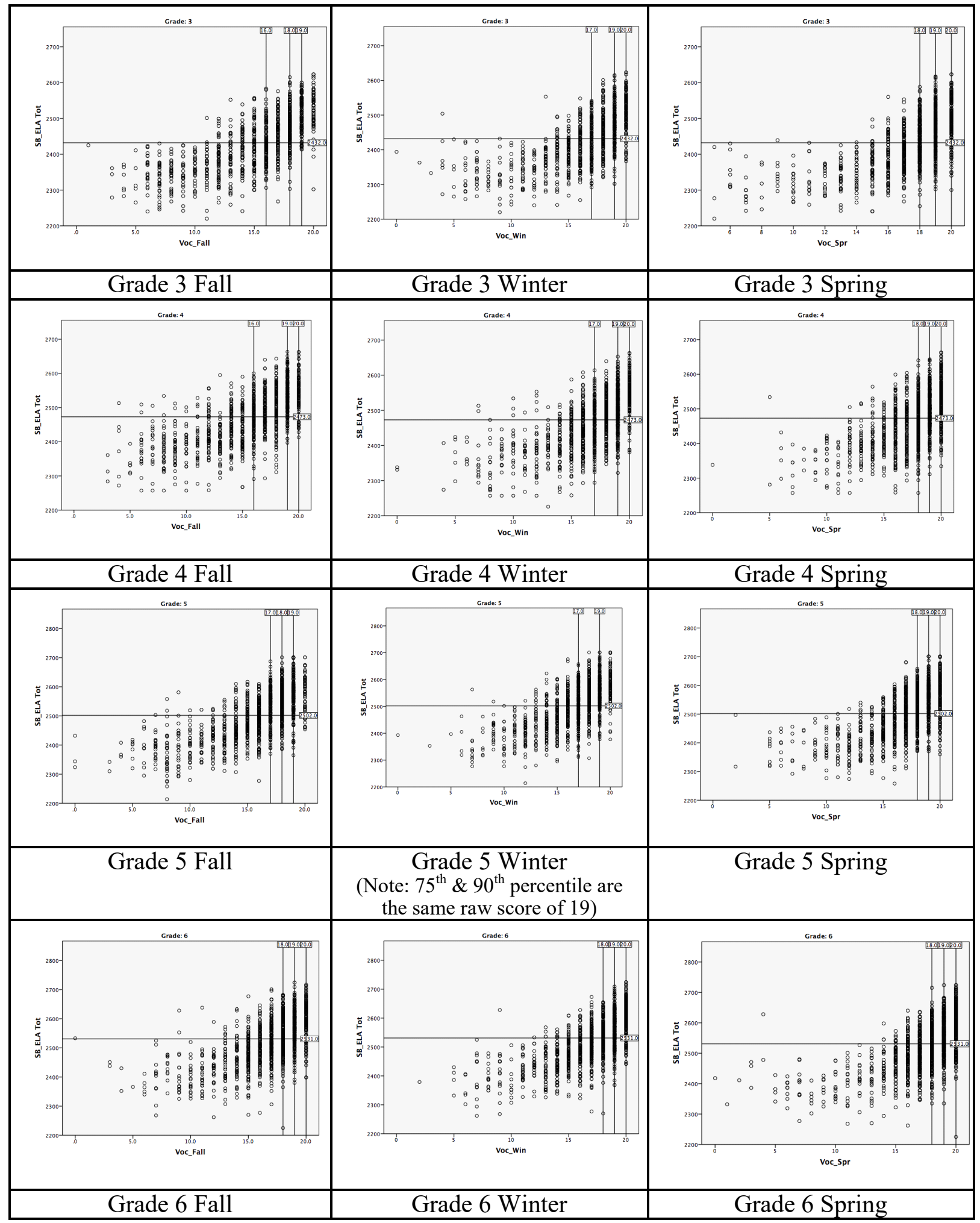

Figure 3. Scatterplots Showing Relation between easyCBM Vocabulary (Voc) and SB ELA Total Score (vertical lines indicate easyCBM norms at the $50^{\text {th }}, 75^{\text {th }}$, and $90^{\text {th }}$ percentile, from left to right; horizontal line indicates SB "Proficient" cut score). 


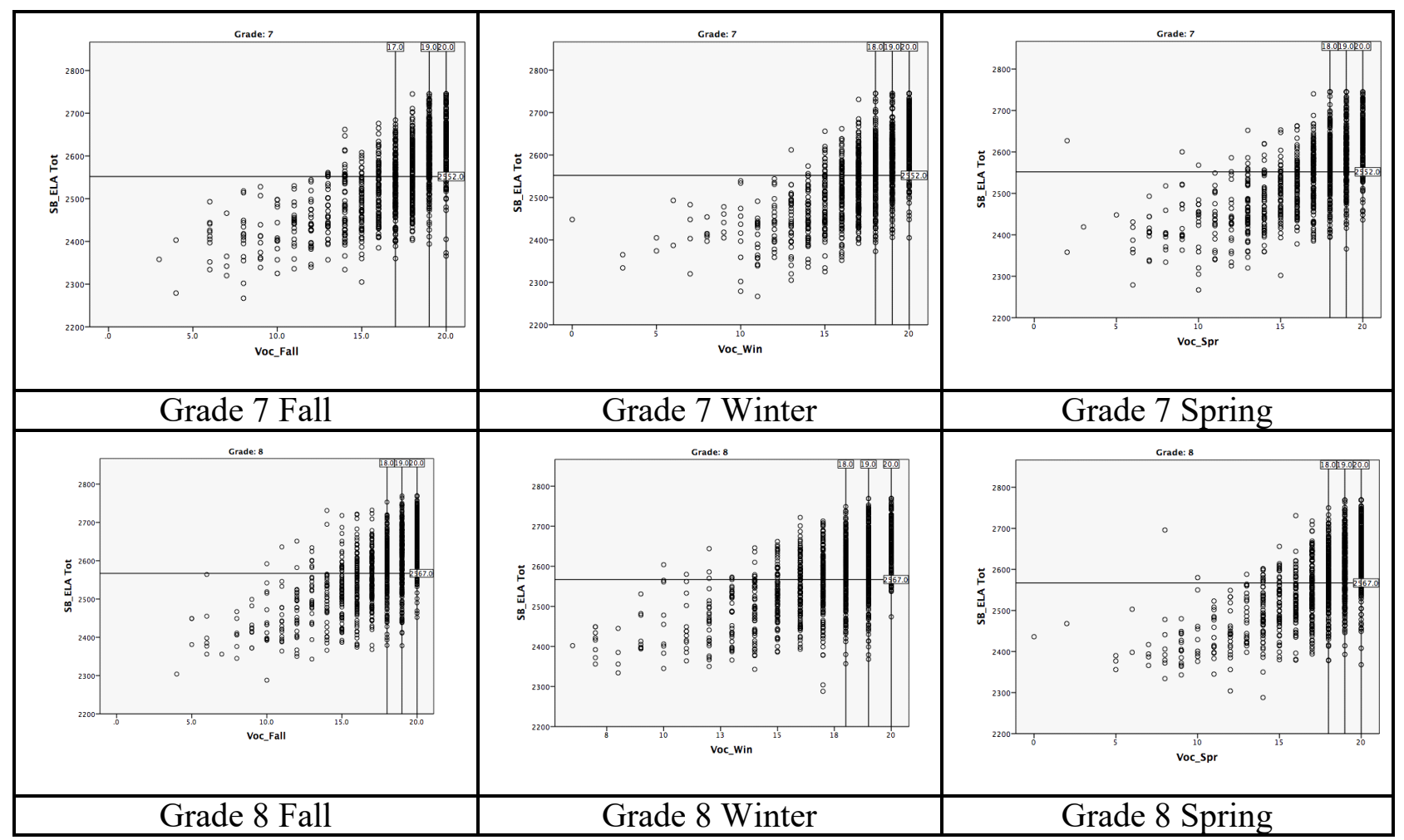

Figure 3 (Continued). Scatterplots Showing Relation between easyCBM Vocabulary (Voc) and SB ELA Total Score (vertical lines indicate easyCBM norms at the $50^{\text {th }}, 75^{\text {th }}$, and $90^{\text {th }}$ percentile, from left to right; horizontal line indicates SB "Proficient" cut score). 


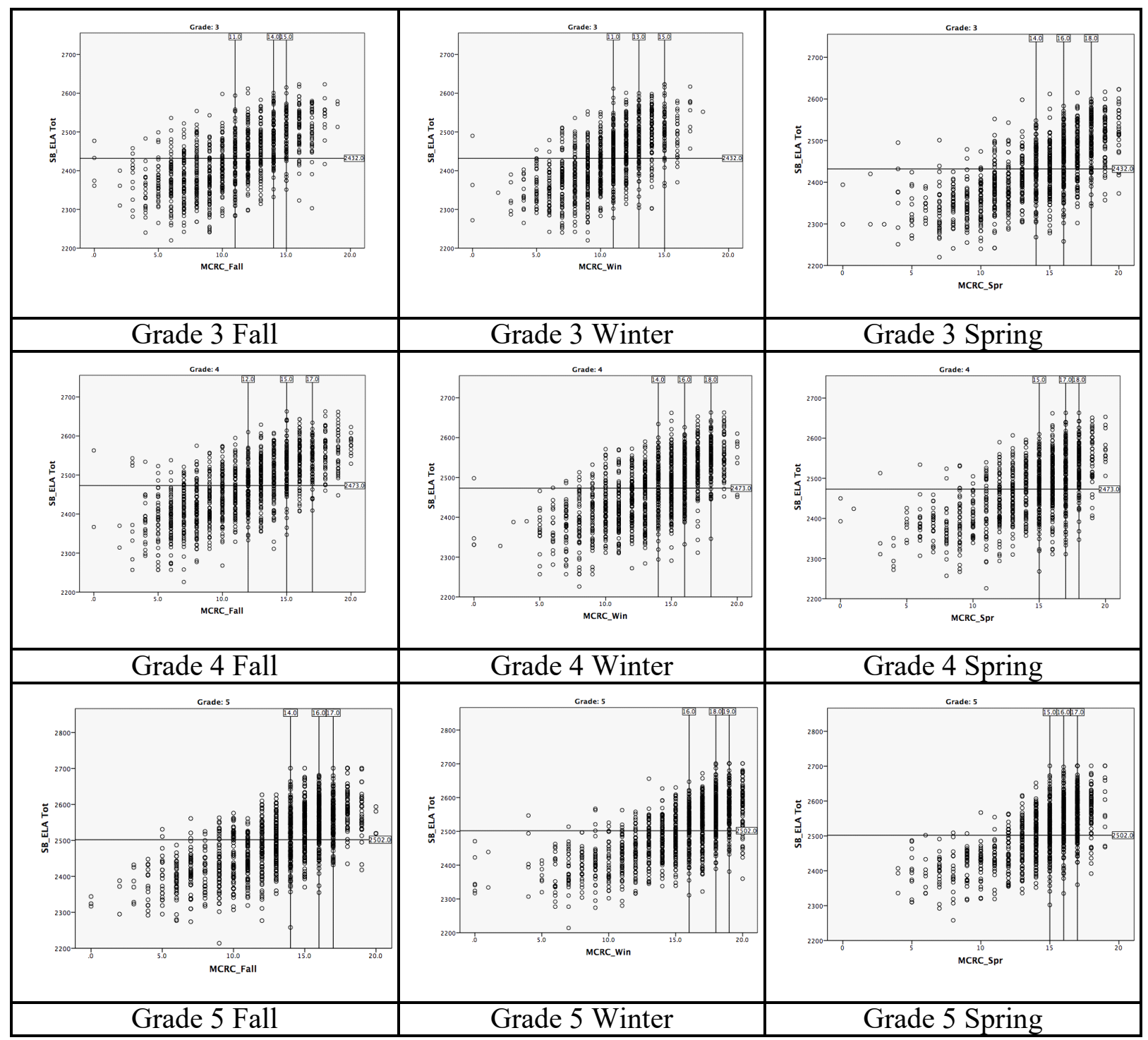

Figure 4. Scatterplots Showing Relation between easyCBM MCRC and SB ELA Total Score (vertical lines indicate easyCBM norms at the $50^{\text {th }}, 75^{\text {th }}$, and $90^{\text {th }}$ percentile, from left to right; horizontal line indicates SB "Proficient" cut score). 


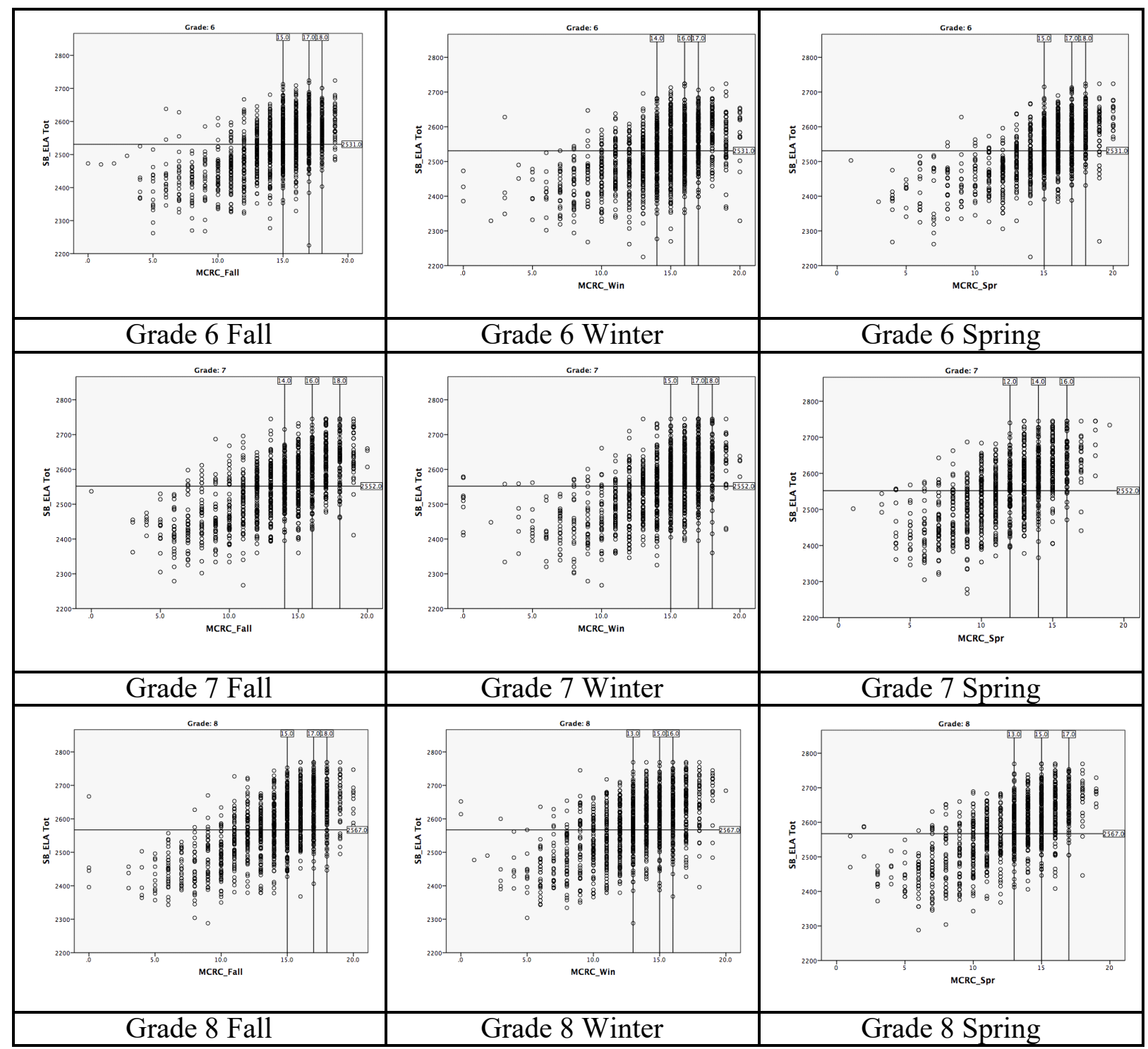

Figure 4 (Continued). Scatterplots Showing Relation between easyCBM MCRC and SB ELA Total Score (vertical lines indicate easyCBM norms at the $50^{\text {th }}, 75^{\text {th }}$, and $90^{\text {th }}$ percentile, from left to right; horizontal line indicates SB "Proficient" cut score). 